International Journal of Social Science and Economic Research

ISSN: $2455-8834$

Volume: 05, Issue: 03 "March 2020"

\title{
EMPIRICAL TESTS OF STOCK MARKET BUBBLES IN CHINA BASED ON GSADF METHOD
}

\author{
Hengyu Yao \\ College of Economics and Management, Nanjing University of \\ Aeronautics and Astronautics, Nanjing 210016, China
}

DOI: 10.46609/IJSSER.2020.v05i03.004 URL: https://doi.org/10.46609/IJSSER.2020.v05i03.004

\begin{abstract}
Taking the two representative stock price indices, namely the Shanghai Composite Index and the Shenzhen Composite Index, as the research objects, this paper first of all makes a concrete analysis of the operation of Chinese stock market, and analyzes the possibility of the existence of stock market bubbles in China from the perspectives of return and volatility, P/E ratio, P/B ratio and turnover ratio. Secondly, this paper attempts to test the existence of bubbles in the two stock price indices, using closing price, $\mathrm{P} / \mathrm{E}$ ratio and $\mathrm{P} / \mathrm{B}$ ratio as proxy variables for bubbles, based on GSADF method. The results confirm the existence of bubbles in Chinese stock market during the sample period, and the results of $\mathrm{P} / \mathrm{B}$ ratio series as the proxy for the bubble level are more significant. Finally, this paper using GSADF method verifies two stock market bubbles in China in 2007 and 2015, respectively, and the former lasted 10 months or more, while the latter lasted only 1-2 months.
\end{abstract}

Keywords: Stock market bubbles; Multiple bubbles; GSADF method

\section{INTRODUCTION}

Stock market bubble is an important factor that causes systemic financial risk and affects the stable operation of financial system. The exuberance of bubbles leads to the misallocation of capital, which makes the capital market unable to serve the real economy effectively, while the collapse of bubbles often triggers serious financial crisis, which is followed by the recession of macro-economy. Therefore, the identification and governance of stock market bubbles has been a hot issue of market concern. This paper begins with the formation mechanism and the identification methods of bubbles, and makes a detailed study of stock market bubbles in China, which is helpful to monitor the systematic financial risk of Chinese stock market. 


\section{International Journal of Social Science and Economic Research}

ISSN: $2455-8834$

Volume: 05, Issue: 03 "March 2020"

Generally speaking, stock market bubbles can be understood as the phenomenon that the stock price continuously deviates from its fundamental value. Those who agree with this view include and are not limited to Blanchard and Watson (1982) ${ }^{[1]}$, Garber (2000) $)^{[2]}$, Rosser (2000) $)^{[3]}$, and Brunnermeier (2001) ${ }^{[4]}$. However, according to different theories of financial economics, the way and process of stock price deviating from its fundamental value are also different, so there are various bubble theories, which can be roughly divided into rational bubbles and irrational bubbles two categories.

The theory of rational bubbles was first proposed and discussed, which is based on rational expectations and efficient-market hypothesis. Under circumstance of strict model assumptions, rigorous mathematical analysis are used to explore the existence of bubbles, and there are basically two frame systems: partial equilibrium analysis and general equilibrium analysis. The research on rational bubbles by means of partial equilibrium analysis gives certain conditions under which the existence of bubbles could be ruled out, e.g. Diba and Grossman (1988) ${ }^{[5]}$, Blanchard and Fisher (1989) ${ }^{[6]}$. Meanwhile, the research through general equilibrium analysis relates the existence of bubbles to the number of investors and their survival time, e.g. Tirole $(1982)^{[7]}$,Weil $(1987)^{[8]}$. With the development of Game Theory and Information Economics, new vitality has been injected into the rational bubble theory. On the basis of investors' rational expectations, some scholars try to explain the emergence of rational bubbles by relaxing the model hypothesis of market efficiency. There are two main types of research that are much representative: one is the bubble caused by the lack of common knowledge proposed by Allen, Morris and Postlewaite (1993) ${ }^{[9]}$, which concludes that private information, short selling constraints, and non-common knowledge are three necessary conditions for the generation of a bubble. And the other is the bubble model under credit expansion proposed by Allen and Gorton $(1993)^{[10]}$, Allen and Gale $(2000)^{[11]}$ as a result of the information asymmetry and principal agent problem. Two types of rational bubble theory above respectively introduce heterogeneous belief and asymmetric information to study the mispricing phenomenon in the process of rational investors' decision-making and trading in imperfect market environment.

Some scholars try to use the theory and viewpoint of behavioral economics to explain the bubble phenomenon in the financial field, thus forming the irrational bubble theory. The main research results of irrational bubble theory are heterogeneous belief bubble model and limited arbitrage bubble model. Heterogeneous belief bubble model mainly refers to bubbles caused by the combination of the difference of investors' decision-making and trading views with the market constraints, where the difference of investors' views is mainly owing to irrational psychological factors such as overconfidence and herd behavior, and the market constraints mainly refer to short selling constraints and liquidity of assets. Related studies include Miller (1977) ${ }^{[12]}$, Harrison and Kreps (1978) ${ }^{[13]}$, Ofek and Richardson $(2003)^{[14]}$, Hong et al. (2006) ${ }^{[15]}$ and so on. 


\section{International Journal of Social Science and Economic Research}

ISSN: $2455-8834$

Volume: 05, Issue: 03 "March 2020"

Limited arbitrage bubbles exist mainly because rational investors due to some certain risks cannot correct the mispricing of assets by arbitrage in time and effectively. There are three main types of risks that limit rational investors from correcting mispricing of assets: the first is fundamental risk proposed by Shleifer and Summers $(1990)^{[16]}$, in which positive changes in the fundamentals reduce the upward deviation of asset prices from their fundamental values to some extent; the second is noise trader risk proposed by Shleifer and Vishny $(1997)^{[17]}$; the third is synchronization risk proposed by Abreu and Brunnermeier (2002) $)^{[18]}$, which may make rational investors choose to take advantage of bubbles and increase their holdings of bubble assets instead of carrying out arbitrage effectively to eliminate the mispricing of assets, thus pursuing excess return on the premise of bearing the risk of bubble collapse. The bubble research based on the behavioral finance theory is more realistic to consider the investors' bounded rationality and the market frictions. In short, the causes of irrational bubbles can be summarized in terms of both the microeconomic subject and the macroeconomic environment.

After theoretical study on the formation mechanism of bubbles, more empirical research on bubbles emerged, mainly laying emphasis on the test and measurement of bubbles. Most empirical tests of bubbles are based on the theory of rational bubbles, which are generally divided into indirect test methods and direct test methods. The indirect test methods mainly include: variance boundary method, West two-step test, unit root and co-integration test and so on, while the direct test method mainly refers to the Markov regime switching model, which is suitable for testing cyclical bubbles. In the following part, the theoretical basis of the unit root method for bubble testing will be introduced.

\section{THEORETICAL BASIS}

\subsection{Explosive bubbles and ADF test}

The empirical test of bubbles in this paper is based on the rational bubble theory, which holds that stock price consists of two parts, one is the fundamental value, and the other is the rational bubble. Stock prices can therefore be expressed as equation (1):

$P_{t}=P_{t}^{f}+B_{t}=\sum_{i=1}^{\infty} \frac{E_{t}\left(D_{t+i}\right)}{\left(1+r_{f}\right)^{i}}+B_{t}$

The parameter $P_{t}$ represents the stock price, and $P_{t}^{f}$ represents the fundamental value of the stock, which is expected return for future periods discounted by risk-free rate $r_{f}$. The parameter $B_{t}$ represents the bubble component of the stock price. When there is a bubble in the stock price, it can be expressed as the difference between the stock price and the fundamental value of the stock. As is shown in equation (2): 
$B_{t}=P_{t}-P_{t}^{f}=P_{t}-\sum_{i=1}^{\infty} \frac{E_{t}\left(D_{t+i}\right)}{\left(1+r_{f}\right)^{i}}$

According to the no-arbitrage principle, the bubble component must satisfy the condition that is shown in equation (3):

$E_{t}\left(B_{t+1}\right)=\left(1+r_{f}\right) B_{t}$

The formula above can be further rewritten as equation (4):

$B_{t+1}=\left(1+r_{f}\right) B_{t}+\varepsilon_{t}, \varepsilon_{t} \sim i . i . d\left(0, \sigma^{2}\right)$

Because the risk-free rate $r_{f}$ is positive at any time, regression coefficient $1+r_{f}>1$. It is shown that the bubble sequence $B_{t}$ follows a divergent path and can be characterized by an explosive process, in other words, it will not become a stationary sequence even after difference handling.

When there is no bubble, or $B_{t}=0$, both sides of equation (1) minus $D_{t} / r_{f}$ at the same time can be shown in equation (5):

$P_{t}-\frac{D_{t}}{r_{f}}=\sum_{i=1}^{\infty} \frac{E_{t}\left(D_{t+i}\right)}{\left(1+r_{f}\right)^{i}}-\frac{D_{t}}{r_{f}}=\frac{1}{r_{f}} \sum_{i=1}^{\infty} \frac{E_{t}\left(\Delta D_{t+i}\right)}{\left(1+r_{f}\right)^{i-1}}$

The formula above shows that when there is no bubble, the stock price and the stock return have the same order of integration. Therefore, ADF test can be used for logarithmic series of stock prices and future cash flows (such as dividends) to determine whether there is a bubble component in stock prices. If the price series can become a stationary process after difference handling, it shows that there is no bubble and there is cointegration relationship between stock prices and future cash flows.

\subsection{Cyclical bubbles and SADF test}

However, the traditional ADF test method is no longer effective for the cyclical bubbles with nonlinear characteristics, which is called the "bubble test trap". In order to overcome the above shortcomings of the linear method, Phillips et al. (2011) ${ }^{[19]}$ proposed SADF test method based on the right-sided $\mathrm{ADF}$ test.

For the time series $y_{t}$, which represents stock prices, consider the recursive least square estimation autoregression as shown in equation (6):

$y_{t}=\mu+\rho y_{t-1}+\sum_{j=1}^{J} \varphi_{j} \Delta y_{t-j}+\varepsilon_{t}, \varepsilon_{t} \sim i . i . d$ 


\section{International Journal of Social Science and Economic Research}

ISSN: $2455-8834$

Volume: 05, Issue: 03 "March 2020"

where $\Delta y_{t-j}$ is the first order difference of the stock price at the end of $t-j$ period. Compared with the alternative hypothesis of traditional ADF tests $H_{1}: \rho<1$, the alternative hypothesis of SADF method based on the right-sided test is $H_{1}: \rho>1$, where $\rho=1+c / k_{n}, c>0, k_{n} \rightarrow \infty$. $k$ represents the lag and $n$ is the number of samples. The test statistic ADF of the estimated coefficient $\rho$ can be calculated as shown in equation (7):

$A D F=\frac{\widehat{\rho}-1}{\operatorname{se}(\widehat{\rho})}$

where $\hat{\rho}$ and $s e(\hat{\rho})$ represent the estimated coefficient and its standard error of the least squares regression based on the given samples respectively. On this basis, the calculation ideas of the SADF test are as follows: For given $T$ observation samples, we first set a minimum regression window width $r_{0}$, and then extend the regression sample size $T_{w}$ to form several sub-samples, each of which calls for the least squares regression and the right-sided test. For the sub-sample, the starting point of regression samples is $r_{1}$, which is the proportion of the sample size before starting point to the total sample size, the ending point of regression samples is $r_{2}$, which is the proportion of the sample size before ending point to the total sample size, and the window width of regression samples is $r_{w}$, which is the proportion of the regression sample size to the total sample size, thus $r_{2}=r_{1}+r_{w}$, and right-sided ADF statistics denoted by $A D F_{r_{1}}^{r_{2}}$. Starting from $r_{1}=0$, the regression window width $r_{w}$ is extended from the minimum regression window width $r_{0}$ to 1 (the full sample). SADF statistics are defined as the sup of a series of right-sided ADF statistics that are associated with the minimum regression window width $r_{0}$, can therefore be represented as equation (8):

$\operatorname{SADF}\left(r_{0}\right)=\sup _{r_{2} \in\left[r_{0}, 1\right]} A D F_{0}^{r_{2}}$

The SADF statistic needs to be compared with the corresponding critical value (usually obtained by Monte Carlo simulation). If the SADF statistic is greater than the critical value, the null hypothesis that a unit root exists is rejected, indicating the existence of the stock market bubble.

\subsection{Multiple bubbles and GSADF test}

In SADF test, the starting point of regression samples is fixed at 0 , which results in this method is only effective for identifying the single cyclical bubble and its duration, however, the possible existence of multiple cyclical bubbles in the samples with large time span could not be detected completely. In response to this question, Phillips, $\mathrm{Wu}$ and $\mathrm{Yu}(2015)^{[20][21]}$ further improved SADF method and proposed the GSADF method. 
International Journal of Social Science and Economic Research

ISSN: $2455-8834$

Volume: 05, Issue: 03 "March 2020"

GSADF method refers to a generalized sup ADF (GSADF) method to test for the presence of bubbles as well as a recursive backward regression technique to time-stamp the bubble origination and termination dates. It relies on recursive right-tailed ADF tests but use flexible window widths in their implementation. Instead of fixing the starting point of the recursion on the first observation, the GSADF test extends the sample coverage by changing both the start point and the endpoint of the recursion over a feasible range of flexible windows. This test is therefore a right-sided double recursive test for a unit root. We define the GSADF statistic to be the largest ADF statistic in this double recursion over all feasible ranges of $r_{1}$ and $r_{2}$, and we denote this statistic by GSADF $\left(r_{0}\right)$ as shown in equation (9):

$\operatorname{GSADF}\left(r_{0}\right)=\sup _{r_{2} \in\left[r_{0}, 1\right], r_{1} \in\left[0, r_{2}-r_{0}\right]} A D F_{r_{1}}^{r_{2}}$

The GSADF statistic also needs to be compared with the corresponding critical value (usually obtained by Monte Carlo simulation). In the same way, if the GSADF statistic is greater than the critical value, the null hypothesis that a unit root exists is rejected, indicating the existence of stock market bubbles.

For time-stamping the origination and termination dates of multiple bubbles, the identification formula is as follows in equation (10) and equation (11):

$\hat{r}_{i e}=\inf _{r_{2} \in\left[r_{0}, 1\right]}\left\{r_{2}: G S A D F_{i r_{2}}\left(r_{0}\right)>s c v_{r_{2}}^{\beta_{T}}\right\}$

$\hat{r}_{i f}=\inf _{r_{2} \in\left[\hat{r}_{i e}+\delta \log (T) / T, 1\right]}\left\{r_{2}: G S A D F_{i r_{2}}\left(r_{0}\right)<s c v_{r_{2}}^{\beta_{T}}\right\}$

where $s c v_{r_{2}}^{\beta_{T}}$ is $100\left(1-\beta_{\mathrm{T}}\right) \%$ critical value of the GSADF statistic based on $\left[\operatorname{Tr}_{2}\right]$ observations. The significance level $\beta_{\mathrm{T}}$ depends on the sample size $T$ and it is assumed that $\beta_{\mathrm{T}} \rightarrow$ 0 as $T \rightarrow \infty$. In empirical applications, it is also often convenient to fix $\beta_{\mathrm{T}}$ at some predetermined level such as 0.05 instead of using a drifting significance level. Accordingly, we define the origination date of a bubble as the first observation whose GSADF statistic exceeds the critical value of the GSADF statistic. The termination date of a bubble is calculated as the first observation after $\left[T \hat{r}_{i e}\right]+\delta \log (T)$ whose GSADF statistic falls below the critical value of the GSADF statistic. For a bubble to be defined, it is here assumed that its duration should exceed a minimal period represented by $\delta \log (T)$, where $\delta$ is a frequency-dependent parameter.

The GSADF method gradually becomes the most effective and widely used in bubble tests since proposed, thus it will be preferred in this paper.

\section{OVERVIEW OF STOCK MARKET IN CHINA}




\section{International Journal of Social Science and Economic Research}

ISSN: $2455-8834$

Volume: 05, Issue: 03 "March 2020"

In this paper, two representative stock price indices, the Shanghai Composite Index and the Shenzhen Composite Index, are taken as the research objects. Monthly data of the closing price, turnover rate, $\mathrm{P} / \mathrm{E}$ and $\mathrm{P} / \mathrm{B}$ of the above-mentioned stock price indices from January 2000 to September 2019 (a total of 237 months) are selected. In this chapter, we study the change trend of a series of quantitative indicators of the stock market operation, and make a qualitative analysis and characteristic summary of stock market in China.

\subsection{Return and volatility}

First the closing price data of two stock price indexes are treated by logarithmic method, and the corresponding return data are obtained as follows in equation (12):

$R_{i, t}=100\left(\ln P_{i, t}-\ln P_{i, t-1}\right)$

Where $R_{i, t}$ represents the log return of the type $i$ stock price index during period $t$, and $P_{i, t}$ represents the closing price of the type $i$ stock price index at the end of period $t$.

Figure 1 shows the movements of the two stock price indices (above), the Shanghai Composite Index and the Shenzhen Composite Index, and their monthly returns (below) over the sample period.

As can be seen from the above half of Figure 1, the movements of the two stock price indices in the sample period are basically the same: from 2001 to 2005, they both showed a downward trend, and from 2006 to 2007, they showed a rare bull market, the stock price indices continued to rise and hit their highest level ever. Then the stock price indices underwent a rapid and deep downside correction in response to the financial crisis triggered by the United States subprime mortgage crisis, until the end of 2008, the stock price indices basically bottomed out. From 2009 to 2014, after some upward correction, the stock price indices experienced a long period of turbulence and a downward trend, until the beginning of 2015, there was another wave of rapid rise; however, the duration of this rising market was short, it terminated in 2015. In 2016-2017, the overall stock market showed a moderate upward trend, until the beginning of 2018, there was a relatively large decline.

As can be seen from the below half of Figure 1, the returns of the two stock price indices, the Shanghai Composite Index and the Shenzhen Composite Index, have shown the characteristics of volatility clustering in 2007-2008 and 2015, therefore, we reasonably speculate that there may be a price bubble in the Chinese stock market during the above-mentioned period. 


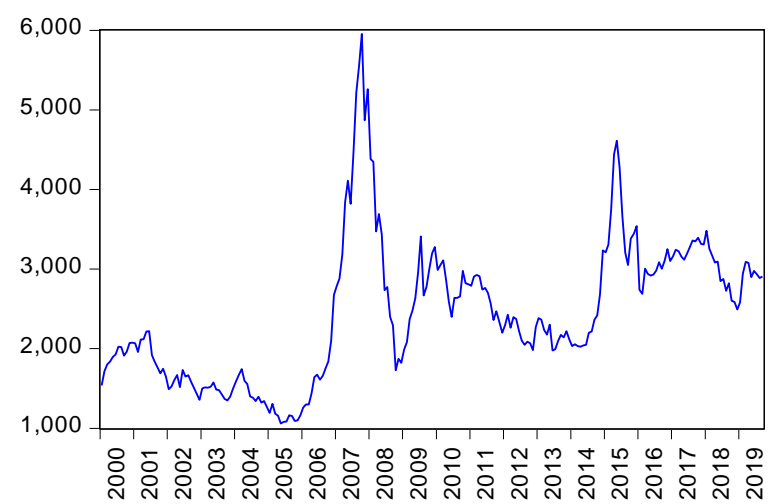

Shanghai Composite Index

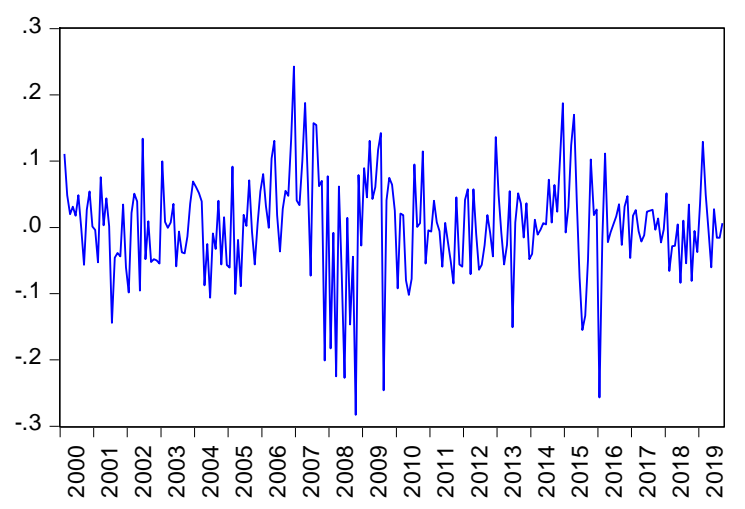

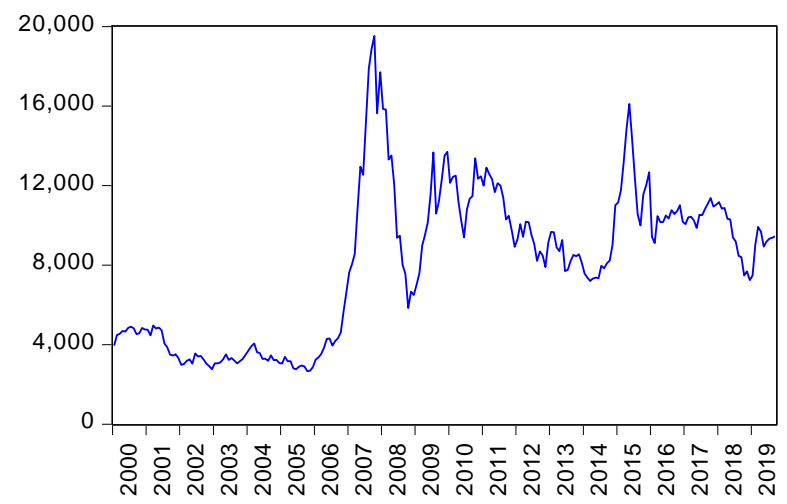

Shenzhen Composite Index

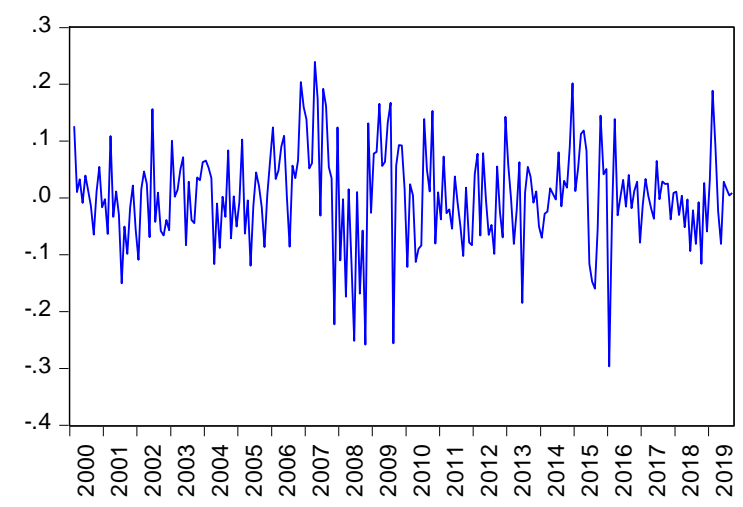

Fig. 1: Time series of monthly prices and returns of the two stock price indices

At the same time, the descriptive statistical results of the returns of the two stock price indices, the Shanghai Composite Index and the Shenzhen Composite Index, are shown in Table 1. It can be seen from the table above that the distributions of the two stock price indices have the characteristics of left-skewed, leptokurtosis and fat-tail. The Shanghai Composite Index has a range of $[-28.28,24.25]$ and a standard deviation of 8.22, while the Shenzhen Composite Index has a range of $[-29.62,23.98]$ and a standard deviation of 9.24. From the volatility of the returns (standard deviation), there is a large price fluctuation in Chinese stock market, suggesting the possibility of a bubble.

Table 1: The descriptive statistical results of the returns of the two stock price indices

\begin{tabular}{cccccccc}
\hline & Max & Min & Avg. & Std. & Skewness & Kurtosis & Jarque-Bera \\
\hline Shanghai Composite Index & 24.25 & -28.28 & 0.53 & 8.22 & -0.62 & 4.82 & $34.89^{* * *}$ \\
Shenzhen Composite Index & 23.98 & -29.62 & 0.63 & 9.24 & -0.38 & 3.86 & $9.61 * * *$ \\
\hline ***, **, * respectively represents rejecting the null hypothesis at 1\%, 5\% and 10\% significance level.
\end{tabular}




\section{International Journal of Social Science and Economic Research}

ISSN: $2455-8834$

Volume: 05, Issue: 03 "March 2020"

\subsection{P/E and P/B}

$\mathrm{P} / \mathrm{E}$ ratio is the ratio of stock price divided by earnings per share. It is one of the most important indices to evaluate whether the valuation level of a stock or a stock market is reasonable. Priceto-book ratio is the ratio of stock price divided by net assets per share. It is also an important index to describe the valuation and risk of stock investment. Generally speaking, a high P/E or $\mathrm{P} / \mathrm{B}$ ratio means that the valuation level of the stock market is too high, there may be a certain degree of stock market bubble.

Figure 2 and Figure 3 respectively show the movements of the P/E (TTM) and P/B (LF) of the two stock price indices, namely the Shanghai Composite Index and the Shenzhen Composite Index. As can be seen from the figures, the valuation level of Chinese stock market has experienced three rounds of sharp rise and fall during the sample period: The first time was from 2006 to 2008, the second time was from 2009 to 2010, and the third time was from 2014 to 2015 .

From the angle of P/E (TTM) ratio, before 2006, the P/E of the Shanghai Composite Index was higher than that of the Shenzhen Composite Index, but the overall downward range was large as the same. The P/E ratio of the Shanghai Composite Index dropped from more than 60 times to about 20 times, the P/E ratio of the Shenzhen Composite Index dropped from more than 50 times to about 10 times. After 2006, the P/E (TTM) of the two stock price indices went up for the first time. Although the initial levels of the two indices were different, but both jumped to about 50 times in the third quarter of 2007 (the Shanghai Composite Index reached a high stage of 51.47 in October 2007, and the Shenzhen Composite Index reached a high stage of 50.25 in September 2007). In October 2008, they reached a low stage of 13.22 and 10.86 respectively. The P/E (TTM) ratio of the Shanghai Composite Index and the Shenzhen Composite Index diverged during the second and third periods: at the end of 2009, the P/E ratio of the Shenzhen Composite Index peaked at more than 60 times, while the Shanghai Composite Index only peaked at more than 30 times in July of that year; the Shenzhen Composite Index peaked at 50.58 in 2015, while the Shanghai Composite Index only peaked at 20.29.

From the point of view of P/B (LF) ratio, before 2006, the trend of two stock price indices is basically the same, both fell from more than 5 times to less than 2 times with occasional upward correction. After 2006, the P/B (LF) trend of the two stock price indices also experienced three sharp rises and falls, and the P/B (LF) ratio of Shenzhen Composite Index has surpassed that of Shanghai Composite Index gradually: the three high peaks of Shenzhen Composite Index are 8.64 in September 2007, 4.62 in July 2009 and 5.12 in May 2015; while three staged highs of the Shanghai Composite Index are 6.84 in October 2007, 3.80 in July 2009 and 2.45 in May 2015. Comparing the three rounds of $\mathrm{P} / \mathrm{B}$ (LF) ratio fluctuation after 2006, we can find that the $\mathrm{P} / \mathrm{B}$ 
movements of the two stock price indices in the second period presents a fluctuating downward trend, clearly different from the sharp decline in the first and third period.

Shanghai Composite Index - Shenzhen Composite Index

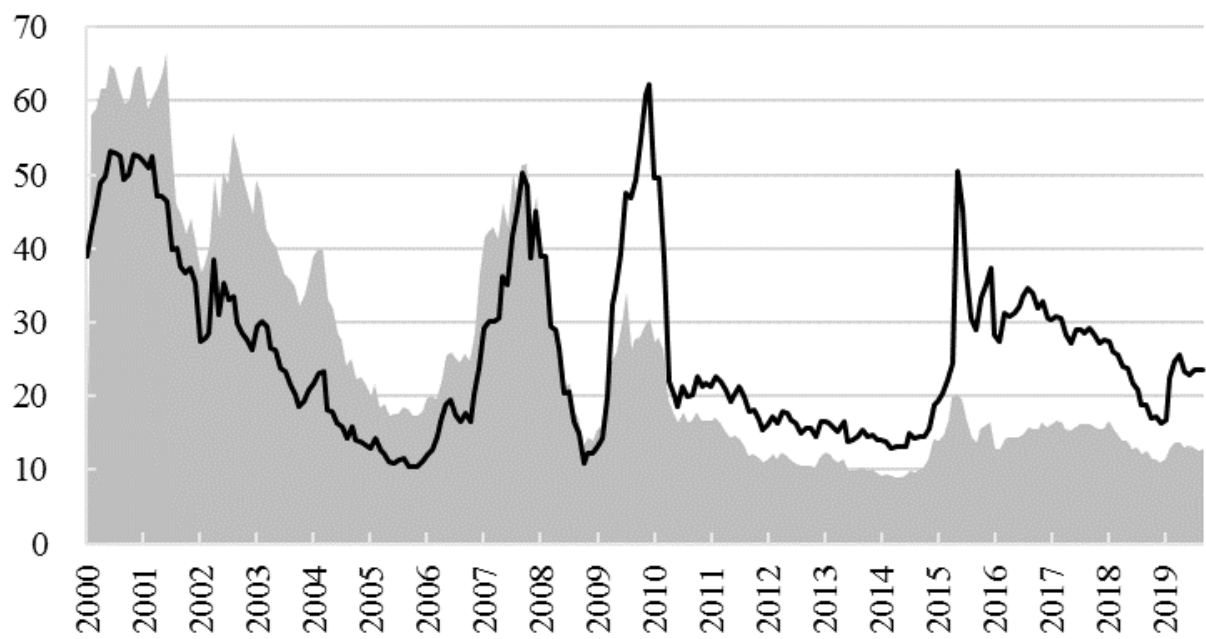

Fig. 2: The P/E (TTM) movements of the two stock price indices
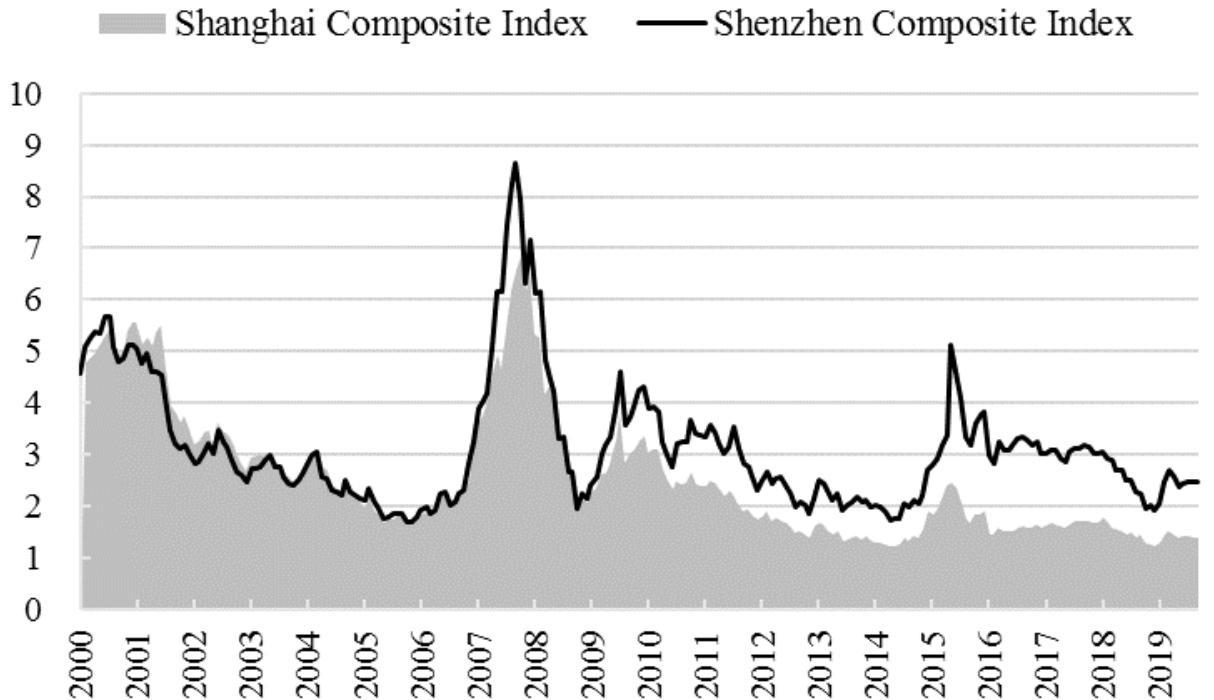

Fig. 3: The P/B (LF) movements of the two stock price indices 


\section{International Journal of Social Science and Economic Research}

ISSN: $2455-8834$

Volume: 05, Issue: 03 "March 2020"

By combining P/E (TTM) ratio and P/B (LF) ratio, we can make a judgment that there is likely to be bubbles in Chinese stock market during 2006-2008 and 2014-2015.

\subsection{Volume and turnover}

Bubbles are often accompanied by a rapid increase in market activity, and market activity will experience a sudden drop due to the collapse of the bubbles. One of the important reference indicators for measuring the activity of the stock market is trading volume. Some investors evaluate the future trend of the stock market price by examining the relationship between trading volume and price: if trading volume keeps going down, the probability that the stock market price continues to fall is big, and the sharp increase in trading volume may be the leading indicator that the stock market takes a turn for the better or stock market bubbles exist, at this time the investors hold strong speculative motives. In addition, the size of trading volume is also related to the total market value of the entire stock market. Due to the continuous entry of new stocks, the total market value of the stock market tends to show a stable growth trend, and the trading volume in theory also naturally expanded. In a long period of time, or in the stock market of rapid growth in total market value, trading volume indicators cannot accurately describe the market activity.

Therefore, we choose the turnover rate as an alternative indicator to examine the sample period of Chinese stock market performance and the possibility of bubbles. Turnover is calculated as the number of shares traded divided by the total number of shares in circulation, or the amount of shares traded divided by the market value of the shares in circulation. The high turnover rate of a stock or a market indicates that the investors hold the stocks for a short time, thus the speculative atmosphere in the market is strong, and the possibility of price bubbles is large. 
International Journal of Social Science and Economic Research

ISSN: $2455-8834$

Volume: 05, Issue: 03 "March 2020"

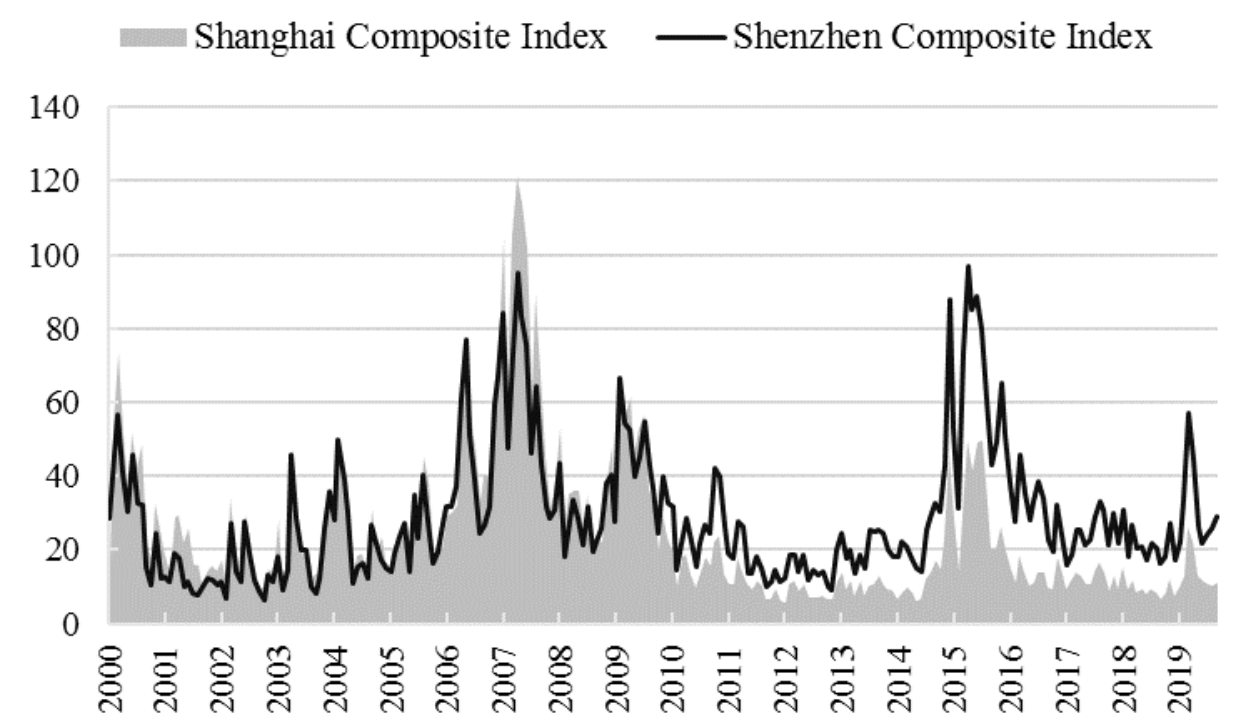

Fig. 4: The turnover rates of the two stock price indices

Figure 4 shows the monthly turnover rates of the Shanghai Composite Index and the Shenzhen Composite Index. It can be seen that the turnover rates of the Chinese stock market during the two periods of 2006-2007 and 2015 are the highest in history, the turnover rates of the two stock price indices had both exceeded 80\%. In April 2007, the turnover rates of the Shanghai Composite Index and the Shenzhen Composite Index were as high as $121.14 \%$ and $95.08 \%$ respectively. In April 2015, the turnover rates of the Shanghai Composite Index and the Shenzhen Composite Index were as high as $49.57 \%$ and $96.77 \%$ respectively. Therefore, we reasonably infer that the two high peaks of turnover rates in 2006-2007 and 2014-2015 imply the high probability of stock market bubbles.

\section{EMPIRICAL TESTS OF STOCK MARKET BUBBLES IN CHINA}

Through investigating the trend of a series of quantitative indicators of two representative stock price indices, namely the Shanghai Composite Index and the Shenzhen Composite Index, such as the closing price, turnover rate, $\mathrm{P} / \mathrm{E}$ and $\mathrm{P} / \mathrm{B}$ ratio, we have conducted a qualitative analysis and summarized the characteristics of Chinese stock market. Next, this paper will use GSADF method to perform empirical tests of stock market bubbles in China.

\subsection{Tests for existence of bubbles}

In this paper, the closing price, $\mathrm{P} / \mathrm{E}$ and $\mathrm{P} / \mathrm{B}$ are used as proxy variables for bubble levels to perform GSADF tests on the two stock price indices respectively. In the GSADF test, the initial length of the regression sample window is 6 months and the step length is 1 month, that is, the 
International Journal of Social Science and Economic Research

ISSN: $2455-8834$

Volume: 05, Issue: 03 "March 2020"

regression sample coverage will be extended by a month after each recursion. Considering the total sample size of 237 , the critical values at $90 \%, 95 \%$ and $99 \%$ confidence levels are obtained by 2000 times simulation. The results of the Shanghai Composite Index are shown in Table 2 and the results of the Shenzhen Composite Index are shown in Table 3.

Table 2: The GSADF test results of the Shanghai Composite Index

\begin{tabular}{|c|c|c|c|c|c|}
\hline \multirow{2}{*}{$\begin{array}{c}\text { Proxy } \\
\text { variables }\end{array}$} & \multirow[t]{2}{*}{$G S A D F$} & \multicolumn{3}{|c|}{$\begin{array}{c}\text { Critical values at different } \\
\text { confidence levels }\end{array}$} & \multirow[t]{2}{*}{ Conclusion } \\
\hline & & $90 \%$ & $95 \%$ & $99 \%$ & \\
\hline closing price & 3.8282 & 2.4325 & 3.0553 & 3.9319 & $\begin{array}{c}\text { There was a bubble at the 5\% } \\
\text { significance level. }\end{array}$ \\
\hline$P / E$ & 3.3479 & 2.0739 & 2.7296 & 3.6847 & $\begin{array}{c}\text { There was a bubble at the } 5 \% \\
\text { significance level. }\end{array}$ \\
\hline$P / B$ & 4.0095 & 1.1243 & 1.5483 & 2.3690 & $\begin{array}{c}\text { There was a bubble at the } 1 \% \\
\text { significance level. }\end{array}$ \\
\hline
\end{tabular}

Table 3: The GSADF test results of the Shenzhen Composite Index

\begin{tabular}{|c|c|c|c|c|c|}
\hline \multirow{2}{*}{$\begin{array}{c}\text { Proxy } \\
\text { variables }\end{array}$} & \multirow[t]{2}{*}{$G S A D F$} & \multicolumn{3}{|c|}{$\begin{array}{l}\text { Critical values at different } \\
\text { confidence levels }\end{array}$} & \multirow[t]{2}{*}{ Conclusion } \\
\hline & & $90 \%$ & $95 \%$ & $99 \%$ & \\
\hline closing price & 4.0983 & 2.3349 & 2.8335 & 4.0135 & $\begin{array}{c}\text { There was a bubble at the } 1 \% \\
\text { significance level. }\end{array}$ \\
\hline$P / E$ & 3.6069 & 2.1479 & 2.6991 & 4.4519 & $\begin{array}{c}\text { There was a bubble at the } 5 \% \\
\text { significance level. }\end{array}$ \\
\hline$P / B$ & 5.5561 & 1.1523 & 1.6416 & 2.4487 & $\begin{array}{c}\text { There was a bubble at the } 1 \% \\
\text { significance level. }\end{array}$ \\
\hline
\end{tabular}

In Table 2, the GSADF statistic value of closing price series is 3.8282, which is higher than the critical value of 3.0553 at $95 \%$ confidence level and lower than the critical value of 3.9319 at $99 \%$ confidence level, it is therefore only feasible to verify the existence of a bubble of the Shanghai Composite Index at a 5\% significance level. Similarly, the GSADF statistic value of the $\mathrm{P} / \mathrm{E}$ series is 3.3479 , which is higher than the critical value of 2.7296 at $95 \%$ confidence level and lower than the critical value of 3.6847 at $99 \%$ confidence level, so the existence of a bubble can only be verified at $5 \%$ significance level as well. It is worth noting that the GSADF statistic value of the $\mathrm{P} / \mathrm{B}$ series of the Shanghai Composite Index is 4.0095 , which is higher than the critical value of 2.3690 at $99 \%$ confidence level, so there is a bubble at the more stringent $1 \%$ significance level.

In Table 3, the GSADF statistic values of the closing price series and the P/B series are 4.0983 and 5.5561 respectively, which are larger than the critical values at $99 \%$ confidence level, so it 
International Journal of Social Science and Economic Research

ISSN: $2455-8834$

Volume: 05, Issue: 03 "March 2020"

can be inferred that there is a bubble of the Shenzhen Composite Index at $1 \%$ significance level. The GSADF statistic value of the P/E series is 3.6069, which is higher than the critical value of 2.6991 at $95 \%$ confidence level and lower than the critical value of 4.4519 at $99 \%$ confidence level, it is therefore only feasible to verify the existence of a bubble at a 5\% significance level.

To sum up, at the level of 5\% significance, the Chinese stock market in the sample period is bound to have a bubble. Of course, the above results also show that the GSADF tests based on $\mathrm{P} / \mathrm{B}$ series is obviously superior to the closing price series and P/E series, therefore, $\mathrm{P} / \mathrm{B}$ will be used as the proxy variable in the following tests for bubble origination and termination dates based on GSADF method.

\subsection{Tests for bubble origination and termination dates}

The tests for bubble origination and termination dates is by comparing the GSADF statistic series of Shanghai Composite Index and Shenzhen Composite Index based on P/B series with their critical value series at 95\% confidence level, to determine when the bubble emerged and collapsed. Figure 5 shows the GSADF statistic series of the Shanghai Composite Index and its critical value series at 95\% confidence level during the sample period, and Figure 6 shows the GSADF statistic series of the Shenzhen Composite Index and its critical value series at 95\% confidence level during the sample period. In the figures, the solid line represents the bubble level of the stock price index, and the dotted line represents the critical value. When the solid line rises above the dotted line, a bubble emerged. Clearly, the bigger the GSADF statistic, the bigger the bubble.

As can be seen from Figure 5, there were two bubbles in the Shanghai Composite Index during the entire sample period. The first bubble lasted from December 2006 to December 2007, with a peak of 4.0095 and lasted for 13 months, while the second bubble lasted from April 2015 to May 2015, with a peak of 1.9752 and lasted only 2 months. Clearly, both in terms of the level and duration of the bubble, the first bubble is more severe than the second one. 


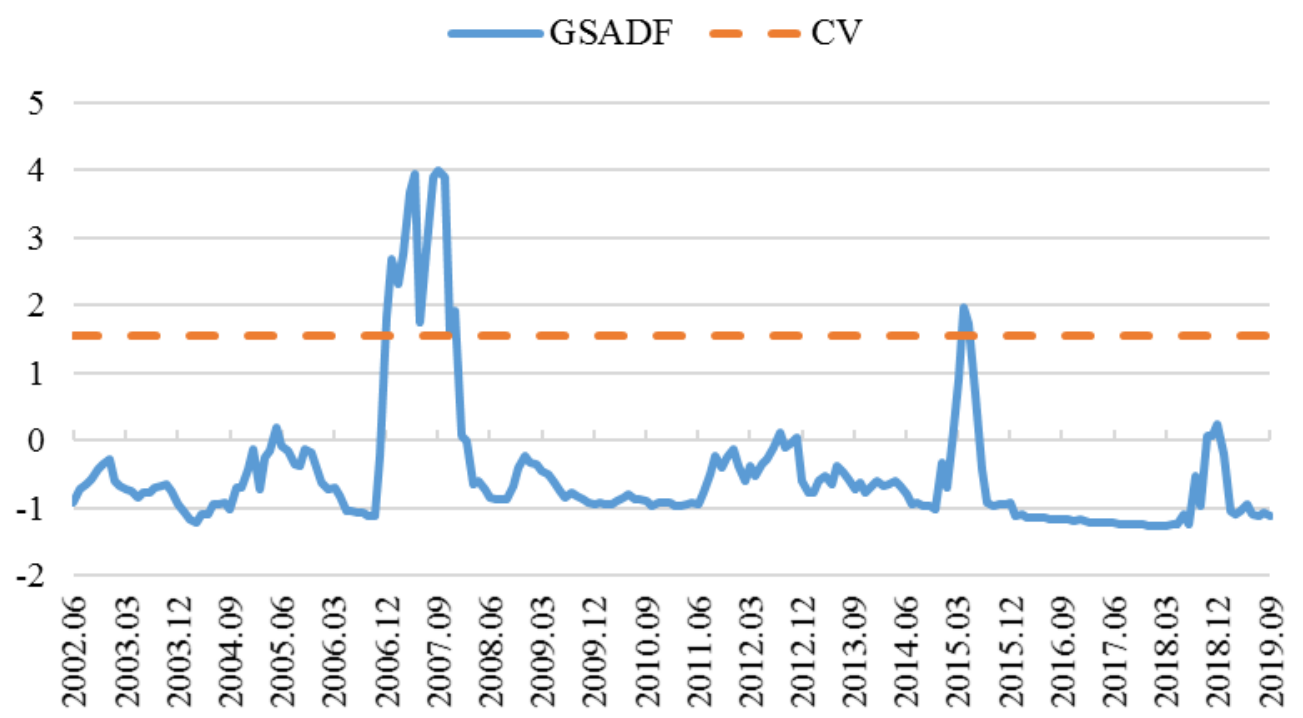

Fig. 5: The bubble origination and termination dates of the Shanghai Composite Index

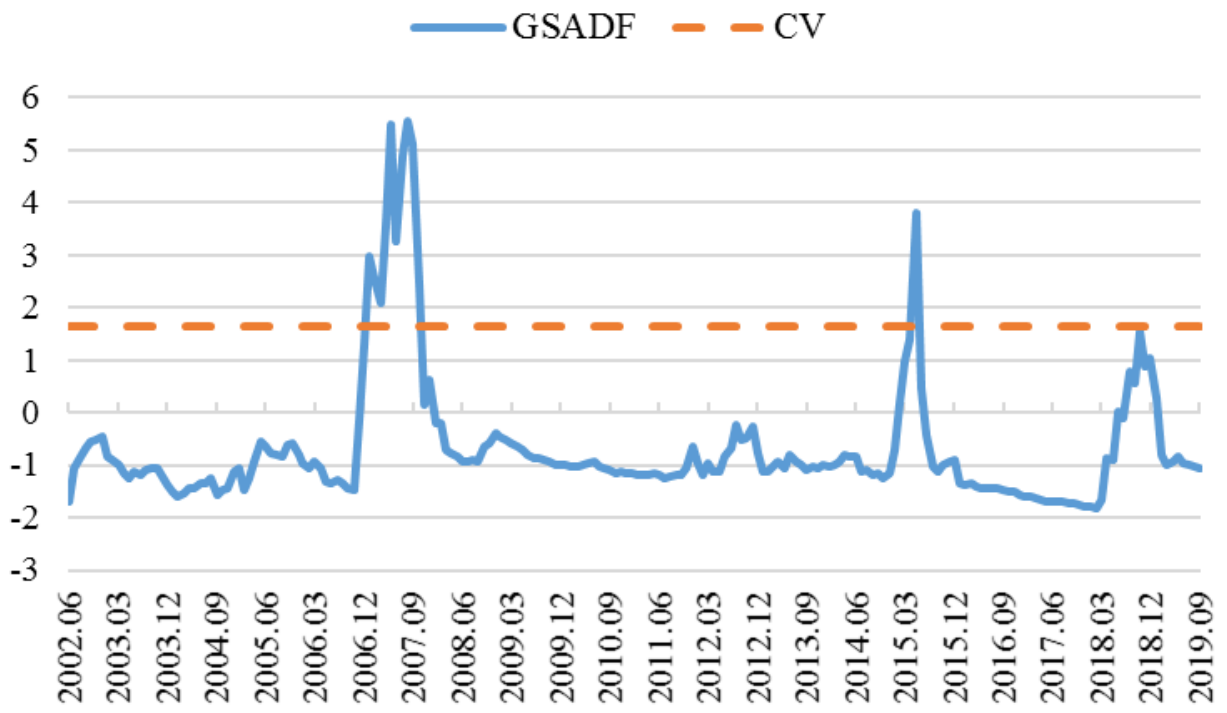

Fig. 6: The bubble origination and termination dates of the Shenzhen Composite Index

As can be seen from Figure 6, the Shenzhen Composite Index also had two bubbles during the whole sample period. The first bubble lasted from January 2007 to October 2007, lasting for 10 months, and peaked at 5.5561. The second bubble peaked at 3.7977 in May 2015 and lasted only one month. Similarly, the empirical results of Shenzhen Composite Index show that the degree of bubble in the first time is more serious than the second time. 


\section{International Journal of Social Science and Economic Research}

ISSN: $2455-8834$

Volume: 05, Issue: 03 "March 2020"

To sum up, we can draw the following conclusion: in 2007 and 2015, there were bubbles in the Chinese stock market, and the stock market bubble collapsed in that year. However, there are great differences in the scale and duration between the two bubbles, which is closely related to the economic situation at home and abroad.

The bubble emerged in 2007, on the one hand, because the domestic GDP maintained a continuous high-speed growth, and the long-term trade surplus and loose monetary policy led to excess liquidity, thus a large number of funds entered into the stock market, driving up the stock prices; on the other hand, the smooth progress of the reform of non-tradable shares and the inflow of foreign capital due to the expectation of RMB appreciation have boosted investor confidence and strengthened their expectation of bull market. Until the outbreak of the financial crisis, a sharp decline in investment, import and export demand, resulting in Chinese economic fundamentals seriously deteriorating and the stock market bubble collapse.

The bubble in 2015 took place during the period when China's economy gradually entered the "new normal". Under the background of the downward pressure on the economy, the stock market rose sharply though. The main reason was still that China continued to implement the loose monetary policy, with the purpose of avoiding a hard landing in the process of economic transformation by providing liquidity to the real economy and reducing financing costs. Under the policy guidance of "deleveraging" by the regulators, the bubble burst quickly after only one to two months because of the lack of fundamental support.

\section{CONCLUSION}

Taking the two representative stock price indices, namely the Shanghai Composite Index and the Shenzhen Composite Index, as the research objects, this paper first of all makes a concrete analysis of the operation of Chinese stock market, and analyzes the possibility of the existence of stock market bubbles in China from the perspectives of return and volatility, P/E ratio, P/B ratio and turnover ratio. Secondly, this paper attempts to test the existence of bubbles in the two stock price indices, using closing price, $\mathrm{P} / \mathrm{E}$ ratio and $\mathrm{P} / \mathrm{B}$ ratio as proxy variables for bubbles, based on GSADF method. The results confirm the existence of bubbles in Chinese stock market during the sample period, and the results of $\mathrm{P} / \mathrm{B}$ ratio series as the proxy for the bubble level are more significant. Finally, this paper using GSADF method verifies two stock market bubbles in China in 2007 and 2015, respectively, and the former lasted 10 months or more, while the latter lasted only 1-2 months.

\section{REFERENCES}

[1] Blanchard, Oliver J., and Mark Watson. Bubbles, Rational Expectations and Financial Markets [Z]. Crisis in the Economic and Financial System, 1982. 
International Journal of Social Science and Economic Research

ISSN: $2455-8834$

Volume: 05, Issue: 03 "March 2020"

[2] Garber, Peter. Famous First Bubbles [M]. MIT Press, 2000.

[3] Rosser, J. Barley. From Catastrophe to Chaos: A General Theory of Economic Discontinuities [M]. Kluwer Academic Publications, 2000.

[4] Brunnermeier, M. K. 2001. Asset pricing under asymmetric information: Bubbles, crashes, technical analysis and herding [M]. Oxford: Oxford University Press.

[5] Diba, B. T., and H. I. Grossman, 1988, The theory of rational bubbles in stock prices, Economic Journal 98: 746-754.

[6] Blanchard, Olivier J., and Stanley Fisher, 1989, "Lectures on Macroeconomics", The MIT Press, Cambridge, Massachusetts, Second Printing.

[7] Tirole, J., 1982, "On the Possibility of Speculation under Rational Expectations", Econometrica, Vol.50, Sept., 1163-1181.

[8] Weil, Philippe, 1987, "Confidence and the Real Value of Money in an Overlapping Generations Economy". Quarterly Journal of Economics, Vol.102, No.1, 1-22.

[9] Allen, F., S. Morris, and A. Postlewaite. 1993. Finite bubbles with short sale constraints and asymmetric information. Journal of Economic Theory 61: 206-229.

[10] Allen, F., and G. Gorton. 1993. Churning bubbles. Review of Economic Studies 60: 813836.

[11] Allen, F., and D. Gale. 2000. Bubbles and Crises, the Economic Journal, Vol.110, No.460, 236-255.

[12] Miller, E. M. 1977. Risk, uncertainty, and divergence of opinion. Journal of Finance 32: 1151-1168.

[13] Harrison, J. M., and D. Kreps. 1978. Speculative investor behavior in a stock market with heterogeneous expectations. Quarterly Journal of Economics 89: 323-336.

[14] Ofek, E., and M. Richardson. 2003. DotCom mania: The rise and fall of Internet stocks, Journal of Finance, 58(3): 1113-1138.

[15] Hong, H., J. Scheinkman, and W. Xiong. 2006. "Asset Float and Speculative Bubbles", Journal of Finance, 61(3): 1073-1117.

[16] Shleifer, A., and L. H. Summers. 1990. "The Noise Trader Approach to Finance", the Journal of Economic Perspectives, 4 (2): 19-33. 
[17] Shleifer, A., and R. W. Vishny. 1997. The limits of arbitrage. Journal of Finance 52: 3555 .

[18] Abreu, D., and M. K. Brunnermeier. 2002. Synchronization risk and delayed arbitrage. Journal of Financial Economics 66: 341-360.

[19] Phillips, P. B., Wu Y., and Yu J. 2011. Explosive behavior in the 1990s NASDAQ: when did exuberance escalate asset values? [J]. International Economic Review, 52(1): 201226.

[20] Phillips, P. B., Shi S. P., and Yu J. 2015. Testing for multiple bubbles I: historical episodes of exuberance and collapse in the SP 500. International Economic Review, 56(4): 1043-1078.

[21] Phillips, P. B., Shi S. P., and Yu J. 2015. Testing for multiple bubbles II: limit theory of real time detector. International Economic Review, 56(4): 1079-1134. 